\title{
Mechanisms and Consequences of Partial Migration in Insects
}

\author{
Myles H. M. Menz ${ }^{1,2,3,4 *}$, Don R. Reynolds ${ }^{5,6}$, Boya Gao ${ }^{7,8}$, Gao Hu ${ }^{8}$, Jason W. Chapman ${ }^{7,8,9}$ \\ and Karl R. Wotton ${ }^{7}$
}

${ }^{1}$ Department of Migration, Max Planck Institute of Animal Behavior, Radolfzell, Germany, ${ }^{2}$ Centre for the Advanced Study of Collective Behaviour, University of Konstanz, Konstanz, Germany, ${ }^{3}$ Department of Biology, University of Konstanz, Konstanz, Germany, ${ }^{4}$ School of Biological Sciences, The University of Western Australia, Crawley, WA, Australia, ${ }^{5}$ Natural Resources Institute, University of Greenwich, Chatham, United Kingdom, ${ }^{6}$ Rothamsted Research, Harpenden, United Kingdom, ${ }^{7}$ Centre for Ecology and Conservation, University of Exeter, Cornwall Campus, Penryn, United Kingdom, ${ }^{8}$ College of Plant Protection, Nanjing Agricultural University, Nanjing, China, ${ }^{9}$ Environment and Sustainability Institute, University of Exeter, Cornwall Campus, Penryn, United Kingdom

\section{OPEN ACCESS}

Edited by:

Brett K. Sandercock,

Norwegian Institute for Nature

Research (NINA), Norway

Reviewed by:

Stephen Baillie Malcolm Western Michigan University,

United States

Michael T. Hallworth,

Northeast Climate Adaptation Science

Center, United States

*Correspondence:

Myles H. M. Menz

mmenz@ab.mpg.de

Specialty section:

This article was submitted to Behavioral and Evolutionary Ecology,

a section of the journal

Frontiers in Ecology and Evolution

Received: 29 May 2019 Accepted: 08 October 2019

Published: 24 October 2019

Citation:

Menz MHM, Reynolds DR, Gao B, Hu G, Chapman JW and Wotton KR (2019) Mechanisms and Consequences of Partial Migration in Insects. Front. Ecol. Evol. 7:403. doi: 10.3389/fevo.2019.00403
Partial migration, where a proportion of a population migrates, while other individuals remain resident, is widespread across most migratory lineages. However, the mechanisms driving individual differences in migratory tendency are still relatively poorly understood in most taxa, but may be influenced by morphological, physiological, and behavioral traits, controlled by phenotypic plasticity and the underlying genetic complex. Insects differ from vertebrates in that partial migration is often associated with pronounced morphological differences between migratory and resident phenotypes, such as wing presence or length. In contrast, the mechanisms influencing migratory tendency in wing-monomorphic insects is less clear. Insects are the most abundant and diverse group of terrestrial migrants, with trillions of animals moving across the globe annually, and understanding the drivers and extent of partial migration across populations will have considerable implications for ecosystem services, such as the management of pests and the conservation of threatened or beneficial species. Here, we present an overview of our current but incomplete knowledge of partial migration in insects. We discuss the factors that lead to the maintenance of partial migration within populations, and the conditions that may influence individual decision making, particularly in the context of individual fitness and reproductive tradeoffs. Finally, we highlight current gaps in knowledge and areas of future research that should prove fruitful in understanding the ecological and evolutionary drivers, and consequences of partial migration in insects.

Keywords: animal migration, flight capacity, intraspecific variation, insect migration, migratory potential, movement ecology, wing polymorphism

\section{INTRODUCTION}

Vast numbers of animals migrate seasonally across large geographic scales, usually due to shifts in resource availability -indeed, the importance of habitat ephemerality as a primary driver of insect migration has long been recognized (Southwood, 1962; Denno et al., 1991; Dingle, 2014) - and also in response to increased predation, parasitism and pathogen pressure (Altizer et al., 2011; Chapman et al., 2015). Migrants connect habitats and populations through their annual movements, but also have profound effects on ecosystem processes such as nutrient fluxes and the provision of ecosystem 
services (Bauer and Hoye, 2014; Bauer et al., 2017; Wotton et al., 2019). There is no universally accepted definition of migration, and many authors take a restricted "vertebratecentric" view and define migration as round-trip movements between discrete "breeding" and "non-breeding" locations, which inevitably excludes most insect examples from this definition. In our review, we adopt a broader view of migration, based on the behavioral definition of Kennedy and Dingle, defined as any movements which are persistent and straightened-out, and characterized by some (temporary) inhibition of behaviors associated with feeding or reproduction (Dingle, 1996, 2014; Dingle and Drake, 2007; Chapman and Drake, 2019). The function of migratory movements is, of course, spatial relocation, but this shift to new habitats is best viewed as a population-level outcome of the individual behaviors. In other words, migration is defined as a behavioral process, with the consequences explained at the ecological or evolutionary level. Other movement ecology researchers might categorize some of the examples we provide in our review as dispersal instead of migration, but we adopt this broad view in order to discuss insect examples in the context of the established framework for partial migration.

"Partial migration," whereby part of a population remains resident while the rest migrates, is a common phenomenon among migratory species (Lack, 1943; Lundberg, 1988; Dingle, 1996, 2014; Chapman et al., 2011; Kokko, 2011; Shaw and Levin, 2011), and has been reported from a wide range of taxa such as fish (Chapman et al., 2012), birds (Nilsson et al., 2011), and mammals (Mysterud et al., 2011; Berg et al., 2019). However, the term has been little used in studies of insects and other invertebrates (but see Hansson and Hylander, 2009; Attisano et al., 2013; Slager and Malcolm, 2015; Dällenbach et al., 2018; Ruiz Vargas et al., 2018; Vander Zanden et al., 2018). Partial migration arises through intra-population variation in migratory tendency, may be driven by physiological, morphological, or behavioral variation (Chapman et al., 2011), and has been proposed to be an early evolutionary stage in the transition to full migration (Berthold, 2001) but, in insects, it could also mark a reversion to residency. Frequency distributions of insect flight duration are often sharply skewed, with short flights significantly more common than long flights (Davis, 1980). Therefore, if short migratory flights become adaptive because overwintering in situ in temperate areas becomes favorable due to warming conditions, short fliers could swiftly replace longdistance migrants in the population. Changes in the frequency of morphs indicates that there must be strong selection for longdistance insect migration to be maintained in the face of the higher mortality rates, physiological costs, and delays to breeding associated with migration (Roff and Fairbairn, 1991; Zera and Denno, 1997; Fox and Dennis, 2010; Bonte et al., 2012; Chapman et al., 2015).

The mechanisms influencing the incidence of partial migration within populations are not well-understood. Three types of partial migration are often recognized in the literature, "breeding," where a population remains together during the non-breeding season, but migrants and residents breed separately, "non-breeding" where a population breeds in the same habitat, but migrants and residents spend the non-breeding season separately and "skipped-breeding" where a population spends the non-breeding season in one location, but part of the population remains and does not breed, while the other migrates to breed (Chapman et al., 2011; Shaw and Levin, 2011; Dingle, 2014). However, these definitions are based on organisms with separate breeding and non-breeding areas, which is often inapplicable to migratory insects, many of which continuously breed year-round with several generations required to complete the migratory cycle (Flockhart et al., 2013; Stefanescu et al., 2013; Chapman et al., 2015). Furthermore, in contrast to vertebrates, migratory insects can show extreme morphological variation between generations, with the production of macropterous morphs, which are long-winged and can undertake migratory flights, brachypterous or micropterous morphs which are short-winged and sedentary, and apterous morphs which are wingless. Short-winged and wingless morphs are unable to migrate and are hereafter referred to collectively as short-winged forms (Johnson, 1969; Roff and Fairbairn, 1991, 2007; Gatehouse and Zhang, 1995; Zera and Denno, 1997; Dingle, 2014). In other cases, the ability to migrate may depend on traits other than wing-length, such as size of the flight muscles or fuel reserves. Thus, whether an individual is migratory or not may come from a "decision" based upon the context in which it finds itself or be pre-determined, for example maternally, as can occur in Hemiptera (Gatehouse, 1994; Vellichirammal et al., 2017).

Here we present an overview of what is known about the incidence and maintenance of partial migration, which is widespread in insects. We contrast the phenomenon in insects and vertebrates, and examine the current terminology used to define the types of partial migration. Knowledge gaps, and fruitful areas for future research, are highlighted. Finally, we argue that insects, with their developmental plasticity and short generation times, provide excellent subjects for investigating the mechanisms that influence migratory decisions.

\section{PARTIAL MIGRATION IN INSECTS}

Insect immature stages (eggs, larvae, nymphs, and pupae) are typically comparatively sedentary compared to adults, so inter-individual differences in migration propensity are generally a feature of the adult stage. Partial migration has been described in a number of insect species from a broad range of orders, such as Hemiptera, Orthoptera, Lepidoptera, Diptera, and Odonata (Figure 1), but much of the work on variation in migratory potential has focused on wingdimorphic hemipterans (Johnson, 1969; Gatehouse and Zhang, 1995; Zera and Denno, 1997; Roff and Fairbairn, 2007; Dingle, 2014). In all cases, it is assumed that an individual will either migrate or remain more-or-less sedentary in one or another life stage in order to increase its overall fitness.

In contrast to most vertebrates, migrant insects are relatively short-lived and usually undergo multiple generations within a year (Chapman et al., 2015). Consequently, defining partial migration into the three main types developed primarily for vertebrates (Chapman et al., 2011; Shaw and Levin, 2011) is inappropriate for insects, particularly due to their short generation times. Some authors have adapted the existing 


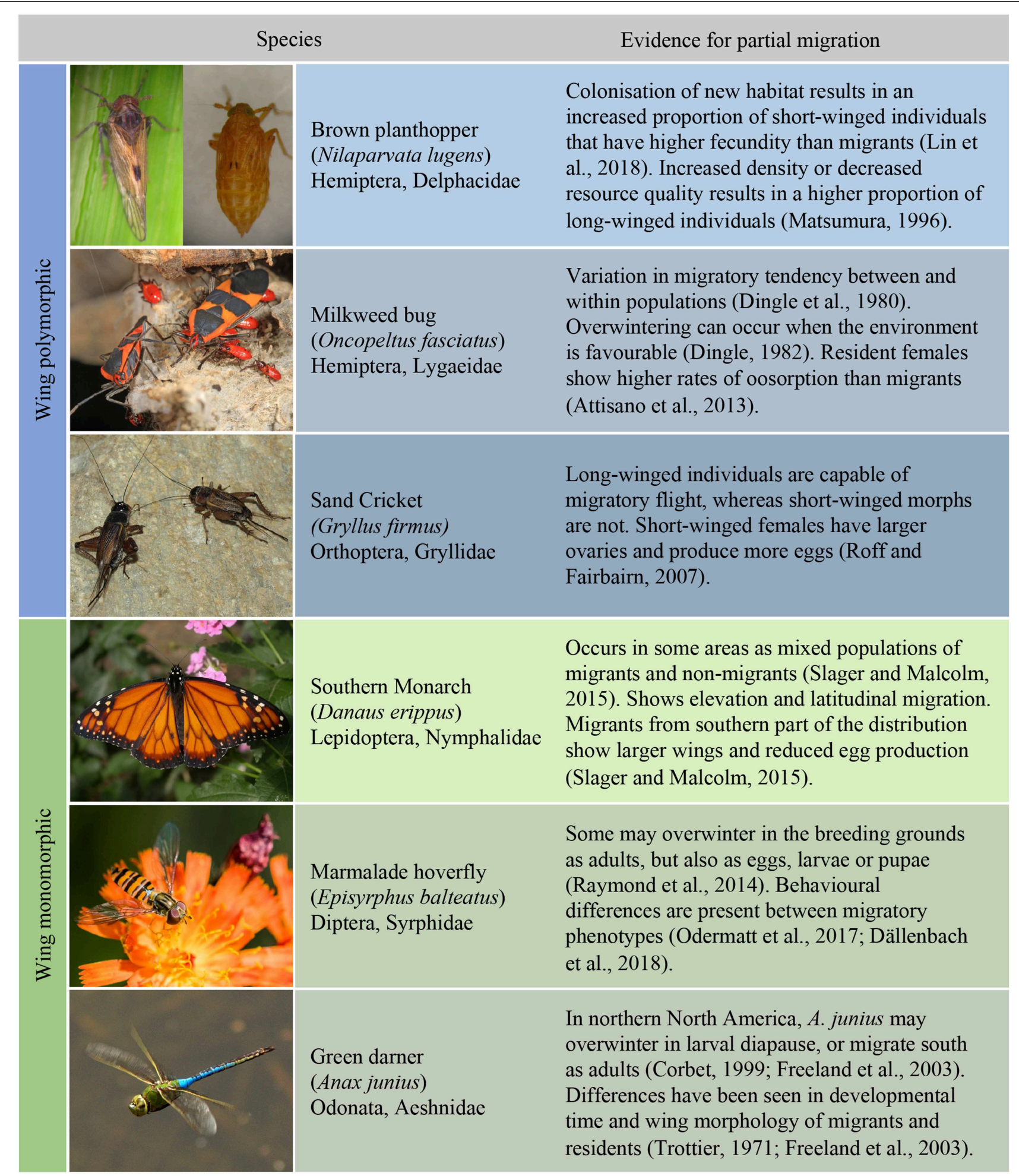

FIGURE 1 | Examples of insect species where partial migration has been studied. In all cases presented here, the migratory cycle consists of a number of generations annually and the proportion of migrants and non-migrants may change between generations. Images: N. lugens, Y. He; O. fasciatus, J. Gallagher (CC BY 2.0); Gryllus firmus, D. Roff; D. erippus, G. Ruellan (CC BY 3.0); E. balteatus, W. Hawkes; A. junius, M. Ostrowski (CC BY-SA 2.0). 


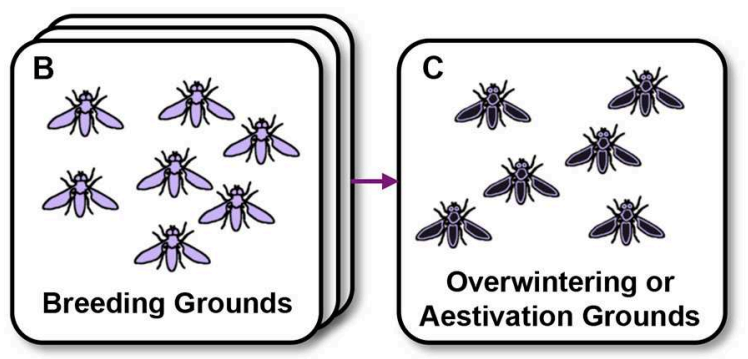

Migrants leave breeding ground to $\mathbf{B}$ or $\mathbf{C}$

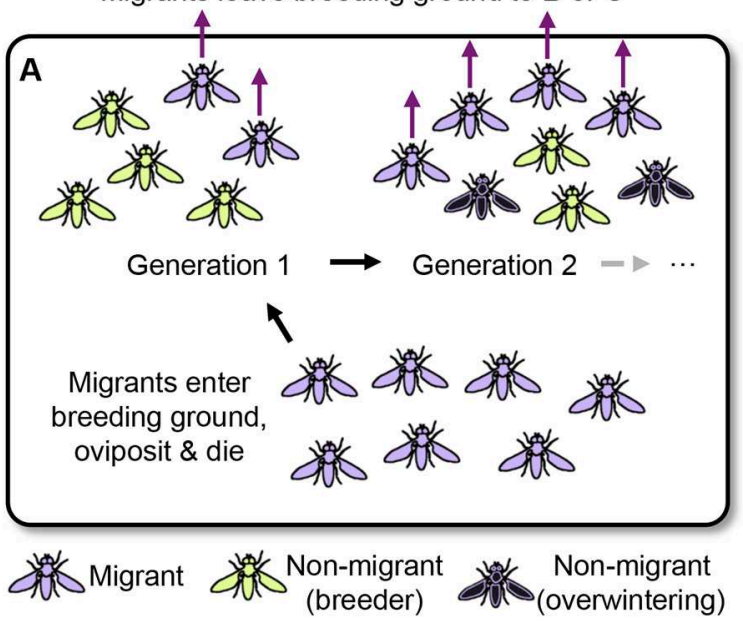

FIGURE 2 | Partial migration in insects. (A) Migrants (colored purple) enter a breeding ground from a previous breeding, overwintering, or aestivation ground. In a northern temperate system this ground may be at lower latitudes. The migrants oviposit creating generation 1 that consists of a varying degree of migrants (purple) and non-migrants (green) depending on the conditions encountered (photoperiod, temperature, resources, population density). Non-migrants act as resident breeders (for example summer generations of monarch butterflies and migratory hoverflies or various flightless morphs of polymorphic species), producing additional generations in the breeding ground that may also consist of varying amounts of migrants or non-migrants. In contrast, the migrants move away from the breeding area becoming temporally separated from the non-migrants, a situation termed sequential partial migration (Ruiz Vargas et al., 2018). (B) Migration to breeding grounds (Class I; Johnson, 1969). Migrants may enter a second breeding ground and the process depicted in (A) continues (and may do so over multiple additional areas). Separate breeding grounds may vary through latitudinal or altitudinal and seasonal clines, and the relative fitness of each morph may vary between successive areas depending on conditions. Migration with multiple phases typically consists of relatively short-lived insects, or morphs of a particular species. Continuously breeding species such as the painted lady butterfly may cycle through this system, while other species may only undertake part of it, for example, aphids, planthoppers and spring migrations of hoverflies (see text for other examples). (C) In some cases, a species may switch to migration to overwintering or aestivation grounds (Class III; Johnson, 1969). Insects with long-distance migration are often relatively long lived, examples include autumn morphs of migrant hoverflies, monarch butterflies and bogong moths. However, overwintering may also take place within the breeding grounds without migration (colored black), such as for migratory hoverflies and the green darner dragonfly. Typically, migration or breeding continues again in the spring.

definitions to suit insects, coining terms such as "sequential partial migration," where migratory and non-migratory animals are separated temporally, rather than spatially (Ruiz Vargas et al., 2018), or "alternate migration," to reflect that some migratory individuals switch from a migratory to a nonmigratory strategy upon encountering a resident population (Vander Zanden et al., 2018). In many cases, sequential partial migration appears apt, as the proportion of migratory and non-migratory individuals change between generations and this definition reflects the multi-generational aspect of insect migration (Figure 2). Broad definitions, such as that a population with 1-99\% migrants can be considered as partially migratory (Chapman et al., 2011), will obviously promote the inclusion of insect taxa. A number of hypotheses have been raised to understand the mechanisms driving individual variability in migratory tendency, and these are discussed further below.

\section{Morphological Variation Between Migrants and Non-migrants}

In comparison to vertebrates, insects can show extreme wing polymorphisms between migratory and non-migratory phenotypes. Consequently, partial migration in insects needs to be considered in terms of the contrast between wing-monomorphic and wing-polymorphic species, as there are likely to be different mechanisms and selection pressures acting on these two fundamentally different types. As most work on the trade-offs between migration and residency has been conducted on wing-polymorphic species, comparing migratory and sedentary phenotypes in wing-monomorphic insects may prove useful for elucidating the underlying mechanisms, but such studies are rare (Tigreros and Davidowitz, 2019).

In birds, there are many examples of differences in body size between migrants and residents, with the latter often being larger, possibly due to larger-bodied individuals having a greater physiological tolerance to overwintering (Ketterson and Nolan, 1976; Belthoff and Gauthreaux, 1991) or the ability to endure periods of low resource availability (Boyle, 2008; Jahn et al., 2010; Chapman et al., 2011). In insects, migrants are often larger than non-migrants (Roff and Fairbairn, 2007), a pattern that has been demonstrated for wing-dimorphic species such as the milkweed bug (Oncopeltus fasciatus) (Hegmann and Dingle, 1982), and gerrid (water-strider) bugs (Fairbairn, 1992), as well as wingmonomorphic species (Altizer and Davis, 2010). Differences in wing loading and morphology have also been reported between migratory and non-migratory monarch (Danaus plexippus) and southern monarch (D. erippus) butterflies, with migrants having larger, more pointed wings and higher wing loads than residents (Dockx, 2007; Altizer and Davis, 2010; Slager and Malcolm, 2015; Vander Zanden et al., 2018), which should result in more fuelefficient flight (Roff and Fairbairn, 1991; Rankin and Burchsted, 1992). Interestingly, no differences in wing morphology were reported between overwintering adults and migrants of the marmalade hoverfly (Episyrphus balteatus; Raymond et al., 2014b). There was also no difference in resting metabolic rate between sexes in E. balteatus, but the smaller females were shown to have higher evaporative water loss than the larger males (Tomlinson and Menz, 2015). 


\section{Reproduction or Migration?}

The costs of migration in relation to reproductive fitness differ between the sexes such that some authors consider that males and females should be considered separately (Johnson, 1969; Gatehouse and Zhang, 1995); here we primarily discuss the relationship as it relates to females. Insect migration is often considered in the context of the "oogenesis-flight syndrome," which posits a trade-off between migration and reproduction (Johnson, 1969; Gatehouse and Zhang, 1995; Dingle, 1996). Development of flight muscles, and migratory flight itself, are energetically costly (Dudley, 1995; Dingle, 2014) and, whereas non-migrants can immediately allocate resources to breeding, migrating individuals will often spend time in reproductive diapause (Johnson, 1969; Rankin and Burchsted, 1992). Migration often occurs pre-reproductively (Gatehouse, 1994; Gatehouse and Zhang, 1995), with reproductive maturity being linked to the cessation of migration, or even the termination of diapause following a period of aestivation or overwintering (Johnson, 1969). However, there is sometimes a more nuanced relationship between reproduction and development of the flight apparatus in wing-monomorphic insects (Rankin et al., 1986; Sappington and Showers, 1992), with some species even migrating with fully-developed oocytes (May et al., 2017; Tigreros and Davidowitz, 2019).

The trade-off between migration and reproduction can be modulated by resource availability in both wing-monomorphic and dimorphic species (Roff and Fairbairn, 2007; Ruiz Vargas et al., 2018). In wing-dimorphic species, the production of macropterous individuals is often determined in early developmental stages or even maternally (Gatehouse, 1994; Wilson, 1995; Ogawa and Miura, 2014; Vellichirammal et al., 2017). Host quality strongly influences wing-morph in brown planthoppers (Nilaparvata lugens); upon colonization of a new resource patch, there is an increased proportion of short-winged individuals, which are unable to migrate but have a greater reproductive potential than the macropterous morph (Lin et al., 2018). As the rice crop matures there is an increase in the proportion of the macropterous form, which can migrate to colonize new rice fields, but the proportion of long-winged individuals within a population can vary between seasons and years (Hu et al., 2017). In aphids, the production of winged morphs may be influenced by environmental conditions such as crowding, decreasing food quality, or the presence of predators (Müller et al., 2001). In wing-monomorphic species, or in long-winged individuals of dimorphic species, the ability to respond to changes in resource availability and switch between a migratory and non-migratory state or vice versa may be driven by differences in physiology, such as the ability to reallocate nutrients from flight to reproduction. Indeed, Attisano et al. (2013) demonstrated that resident female milkweed bugs showed a higher level of oosorption (where females resorb nutrients from developing oocytes thus favoring survival over current reproduction) than did migrants.

\section{Density Dependence}

It has been predicted that an increased proportion of migrants should occur in populations at higher densities (Chapman et al., 2011). In insects, partial migration may allow individuals that move to breed to avoid the negative consequences of resource competition (Taylor and Taylor, 1983; Dingle, 1996). For example, in the planthoppers N. lugens and Sogatella furcifera, an increased proportion of long-winged individuals may be produced at high densities (Matsumura, 1996; Lin et al., 2018). Similarly, crowding can promote the production of winged offspring in aphids (Johnson, 1969; Müller et al., 2001). The lower fecundity typically found in winged forms typically is an example of the tradeoff between the colonization of new habitats and reproductive output.

\section{Predation and Parasitism Risk}

Partial migration may confer some reduction in the risk of predation or parasitism, by movement into an enemy free space, resulting in improved survival for migrants. However, the role of trophic interactions has received relatively little attention in the partial migration literature (Chapman et al., 2011) and has rarely been studied in migratory insects (Altizer et al., 2011; Chapman et al., 2015). Nonetheless, there is evidence that migration can reduce the prevalence of infection from the protozoan parasite, Ophryocystis elektroscirrha in monarchs (Bartel et al., 2011; Altizer et al., 2015; Flockhart et al., 2018), with resident populations having higher infection rates than migrant populations (Satterfield et al., 2015, 2016, 2018), providing evidence of "migratory escape" (Altizer et al., 2011) from contaminated environments.

\section{The Evolution, Expression, and Maintenance of Partial Migration}

Migratory flight tendency has been shown to be heritable in a broad range of insect species, indicating a strong genetic component to migratory behavior (Wilson, 1995; Dingle, 1996, 2014; May et al., 2017; Dällenbach et al., 2018). The capacity of insects to form migrants or non-migrants from within the same population could potentially be determined by genetic polymorphisms, for example alleles that influence flight or timing (Niitepõld et al., 2009; Hut et al., 2013; Zhan et al., 2014) and/or the expression of environmentally-induced phenotypic plasticity. While evidence for a solely genetically determined difference is lacking for partial migration, phenotypically plastic pathways are a widespread feature of insect life histories (Nijhout, 1999) and are likely to provide the predominant mechanisms allowing migrants to switch forms, an idea strengthened by the low level of genetic differentiation and phylogeographic structuring found within many partial migrant populations (Mun et al., 1999; Freeland et al., 2003; Raymond et al., 2013; Zhan et al., 2014).

How discrete migratory states within a population are maintained is unclear, but two hypotheses have been proposed (Chapman et al., 2011). One possibility is the attainment of an evolutionary stable state, where the fitness of each form is balanced by frequency-dependent selection. For example, in wing dimorphic insects where the more fecund flightless form is balanced by the colonizing abilities of the migrant morph (Roff, 1994; Zera and Denno, 1997). Alternatively, the fitness benefits of either morph may occur as a result of conditional strategies, were the decision to migrate is based upon gaining the highest fitness 
possible under certain circumstances and a balancing of fitness is not necessary (Chapman et al., 2011). The generally short life span of insect migrants and their higher reliance on favorable meteorological conditions for migration (Alerstam et al., 2011; $\mathrm{Hu}$ et al., 2016) highlights the importance for selecting the optimal strategy in any given situation. Migratory hoverflies, such as E. balteatus, for example, may migrate south to warmer climes (Wotton et al., 2019) but are also capable of sedentary overwintering behavior as adults, larvae, or pupae (Raymond et al., 2014a), an adaptation that presumably increases their fitness over attempting to migrate in unfavorable conditions (also see Vander Zanden et al., 2018).

The inheritance and phenotypic expression of migratory states has been investigated in both wing polymorphic (Fairbairn and Yadlowski, 1997; Roff et al., 1997) and monomorphic (Kent and Rankin, 2001) insects and interpreted in the context of the "threshold model": a quantitative genetic model for the evolution of polygenic, dichotomous traits (Roff, 1996). Under this model, a normally distributed trait, called the liability, underlies the expression of the migratory dimorphism and a threshold determines the developmental trajectory-in this case migrant or non-migrant. If the liability exceeds the threshold then the individual takes one path, say migration, if not it becomes sedentary. In the case of wing polymorphism, it is hypothesized that the liability for wing production may be governed by hormone profiles at a particular larval stage: in larvae where levels exceed the threshold (conceivably controlled by levels of hormone receptors among other factors) the flightless morph is formed (Oostra et al., 2011; Roff, 2011). An additional consideration is that threshold traits also vary with environmental factors such as temperature, photoperiod, and density (Hondelmann and Poehling, 2007; Guerra and Reppert, 2013). A more realistic model-the environmental threshold model-allows for both genetic variation, and for individual or environmental conditions to modify the threshold and the liability (Roff, 1994; Wikelski et al., 2006; Hallworth et al., 2018; see Pulido, 2011 for a full consideration of the model and its implications for partial migration) and therefore has the potential to provide a comprehensive framework for a deeper understanding of partial migration in insects.

\section{Ecological Implications of Partial Migration in Insects}

Insects are the most abundant and speciose terrestrial migrants, with trillions of individuals undertaking movements annually (Holland et al., 2006; Chapman et al., 2015; Hu et al., 2016). Additionally, many migratory insect species are important agricultural pests (Drake and Gatehouse, 1995), or are beneficial-as pollinators or natural enemies (Wotton et al., 2019) or as food for other animals (Krauel et al., 2015; Warrant et al., 2016). Consequently, understanding the incidence and mechanisms involved in the regulation of partial migration in insect populations has significant implications for ecosystem functioning and species management. Models based on predatorprey dynamics and interactions with environmental conditions have been developed to study the ecosystem effects of partial migration in fish (Brodersen et al., 2008, 2011), and similar approaches may be considered for insects, particularly in the context of nutrient transfer between trophic levels and across landscapes. Furthermore, understanding the factors influencing the level of migration within populations may allow for the implementation of more realistic species management strategies.

\section{Future Directions and Gaps in Knowledge}

Despite the deficiency of research investigating the mechanisms driving partial migration in insects, the phenomenon evidently occurs in numerous species, and there are exciting opportunities for research into the evolution and ecology of the phenomenon. Insects are excellent model systems; they are relatively small, easily maintained, and can be manipulated in a laboratory environment. The opportunity for identifying new partial migration study systems will be facilitated by the huge diversity of migratory insect species and their broad range of life histories.

Little is known about the influence of anthropogenic landscape change on partial migration in insect populations. There is evidence that landscape alterations can readily lead to an increase in the propensity for residency in migratory insects, usually in response to favorable conditions, such as the availability of food resources. For example, increased planting of tropical milkweed (Asclepias curassavica) in Florida has led to an increase in residency in monarchs, but residents suffer from increased parasitism compared to migrants (Satterfield et al., 2015). Urbanization can also increase the propensity for residency or overwintering through the provision of winter refugia or foraging resources, such as garden flowers. Luder et al. (2018) demonstrated that migratory hoverflies appeared earlier in the season in urban areas compared to agricultural areas, indicating that cities may provide favorable conditions for overwintering. Warming temperatures have also led to an increase in overwintering of migratory species in the UK, such as the red admiral butterfly (Vanessa atalanta), although much of the population still immigrates to the UK each spring (Sparks et al., 2005; Fox and Dennis, 2010). Fairly simple laboratory experiments could be used to shed light on whether warming or constant temperatures, or increased food constancy, influences the migratory propensity in wingmonomorphic insects.

Tracking the migratory behavior of insects in the field is difficult, primarily due to their small size and sheer numbers. Individual tracking of insects to determine migratory decisions has been hindered because the majority of species fall well below the body size required to carry active transmitters (Wikelski et al., 2006; Kissling et al., 2014; Knight et al., 2019). Consequently, many studies investigating insect migratory behavior which may be relevant to partial migration have been conducted in the laboratory, using proxy measures for migratory potential, such as flight duration and activity (Minter et al., 2018). Tethered flight experiments have proven useful for determining migratory tendency in a range of insect species (Dällenbach et al., 2018; Minter et al., 2018; Naranjo, 2019). However, the further miniaturization of individual tracking technology will provide exciting opportunities to understand the drivers of partial migration and the mechanisms that influence individual decision-making. The use of intrinsic markers, such as stable isotopes, has proven useful for elucidating the origin of migratory 
insects (Hobson et al., 2012; Flockhart et al., 2013; Hallworth et al., 2018) and is applicable to a range of species. Recent advances in molecular techniques, including metabarcoding of pollen carried on the bodies of insects also shows great promise (Suchan et al., 2019). Techniques using intrinsic markers, where the utility is not limited by the size of the insect, will likely prove key in understanding patterns of partial migration in many insect taxa.

\section{AUTHOR CONTRIBUTIONS}

MM and KW wrote the first draft of the manuscript. All authors contributed to the development of ideas and writing of the manuscript.

\section{REFERENCES}

Alerstam, T., Chapman, J. W., Bäckman, J., Smith, A. D., Karlsson, H., Nilsson, C., et al. (2011). Convergent patterns of long-distance nocturnal migration in noctuid moths and passerine birds. Proc. R. Soc. B 278, 3074-3080. doi: 10.1098/rspb.2011.0058

Altizer, S., Bartel, R., and Han, B. A. (2011). Animal migration and infectious disease risk. Science 331, 296-302. doi: 10.1126/science.11 94694

Altizer, S., and Davis, A. K. (2010). Populations of monarch butterflies with different migratory behaviours show divergence in wing morphology. Evolution 64, 1018-1028. doi: 10.1111/j.1558-5646.2010.00946.x

Altizer, S., Hobson, K. A., Davis, A. K., de Roode, J. C., and Wassenaar, L. I. (2015). Do healthy monarchs migrate farther? Tracking natal origins of parasitized vs. uninfected monarch butterflies overwintering in Mexico. PLoS ONE 10:e0141371. doi: 10.1371/journal.pone.0141371

Attisano, A., Tregenza, T., Moore, A. J., and Moore, P. J. (2013). Oosorption and migratory strategy of the milkweed bug, Oncopeltus fasciatus. Anim. Behav. 86, 651-657. doi: 10.1016/j.anbehav.2013.07.013

Bartel, R. A., Oberhauser, K. S., de Roode, J. C., and Altizer, S. M. (2011). Monarch butterfly migration and parasite transmission in eastern North America. Ecology 92, 342-351. doi: 10.1890/10-0489.1

Bauer, S., Chapman, J. W., Reynolds, D. R., Alves, J. A., Dokter, A. M., Menz, M. H. M., et al. (2017). From agricultural benefits to aviation safety: realizing the potential of continent-wide radar networks. Bioscience 67, 912-918. doi: 10.1093/biosci/bix074

Bauer, S., and Hoye, B. J. (2014). Migratory animals couple biodiversity and ecosystem functioning worldwide. Science 344:1242552. doi: 10.1126/science. 1242552

Belthoff, J. R., and Gauthreaux, S. A. Jr. (1991). Partial migration and differential winter distribution of house finches in the Eastern United States. Condor 93, 374-382. doi: 10.2307/1368953

Berg, J. E., Hebblewhite, M., St. Clair, C. C., and Merrill, E. H. (2019). Prevalence and mechanisms of partial migration in ungulates. Front. Ecol. Evol. 7:325. doi: $10.3389 /$ fevo.2019.00325

Berthold, P. (2001). Bird Migration: A General Survey. Oxford: Oxford University Press.

Bonte, D., Van Dyck, H., Bullock, J. M., Coulon, A., Delgado, M., Gibbs, M., et al. (2012). Costs of dispersal. Biol. Rev. 87, 290-312. doi: $10.1111 / j .1469-185 X .2011 .00201 . x$

Boyle, W. A. (2008). Partial migration in birds: tests of three hypotheses in a tropical lekking frugivore. J. Anim. Ecol. 77, 1122-1128. doi: 10.1111/j.1365-2656.2008.01451.x

Brodersen, J., Ådahl, E., Brönmark, C., and Hansson, L.-A. (2008). Ecosystem effects of partial fish migration in lakes. Oikos 117, 40-46. doi: 10.1111/j.2007.0030-1299.16118.x

Brodersen, J., Nicolle, A., Nilsson, P. A., Skov, C., Brönmark, C., and Hansson, L.-A. (2011). Interplay between temperature, fish partial migration and

\section{FUNDING}

This project has received funding from the European Union's Horizon 2020 research and innovation programme under the Marie Skłodowska-Curie Grant Agreement No. 795568 (awarded to MM). Funding to KW was provided by the Royal Society through a University Research Fellowship (UF150126). Rothamsted Research receives grant-aided support from the United Kingdom Biotechnology and Biological Sciences Research Council (BBSRC). Funding to $\mathrm{GH}$ and $\mathrm{BG}$ were provided by the National Natural Science Foundation of China (31822043) and the Natural Science Foundation of Jiangsu Province (BK20170026).

trophic dynamics. Oikos 120, 1838-1846. doi: 10.1111/j.1600-0706.2011. 19433.x

Chapman, B. B., Brönmark, C., Nilsson, J.-Å., and Hansson, L.-A. (2011). Partial migration: an introduction. Oikos 120, 1761-1763. doi: 10.1111/j.1600-0706.2011.20070.x

Chapman, B. B., Skov, C., Hulthén, K., Brodersen, J., Nilsson, P. A., Hansson, L.-A., et al. (2012). Partial migration in fishes I: definitions, methodologies and taxonomic distribution. J. Fish Biol. 81, 479-499. doi: 10.1111/j.1095-8649.2012.03349.x

Chapman, J. W., and Drake, V. A. (2019). "Insect migration," in Encyclopedia of Animal Behavior, 2nd Edn, Vol. 3, ed. J.C. Choe (Amsterdam: Elsevier, Academic Press), 573-580. doi: 10.1016/B978-0-12-809633-8.01248-6

Chapman, J. W., Reynolds, D. R., and Wilson, K. (2015). Long-range seasonal migration in insects: mechanisms, evolutionary drivers and ecological consequences. Ecol. Lett. 18, 287-302. doi: 10.1111/ele.12407

Corbet, P. S. (1999). Dragonflies - Behaviour and Ecology of Odonata. Colchester, UK: Harley Books.

Dällenbach, L. J., Glauser, A., Lim, K. S., Chapman, J. W., and Menz, M. H. M. (2018). Higher flight activity in the offspring of migrants compared to residents in a migratory insect. Proc. R. Soc. B 285:20172829. doi: 10.1098/rspb.2017.2829

Davis, M. A. (1980). Why are most insects short flyers? Evol. Theory 5, 103-111.

Denno, R. F., Roderick, G. K., Olmstead, K. L., and Dobel, H. G. (1991). Density related migration in planthoppers (Homoptera: Delphacidae): the role of habitat persistence. Am. Nat. 138, 1513-1541. doi: 10.1086/285298

Dingle, H. (1982). Function of migration in the seasonal synchronization of insects. Ent. Exp. Appl. 31, 36-48. doi: 10.1111/j.1570-7458.1982.tb03117.x

Dingle, H. (1996). Migration: The Biology of Life on the Move. New York, NY: Oxford University Press.

Dingle, H. (2014). Migration: The Biology of Life on the Move, 2nd Edn. New York, NY: Oxford University Press. doi: 10.1093/acprof:oso/9780199640386.001.0001

Dingle, H., Blakley, N. R., and Miller, E. R. (1980). Variation in body size and flight performance in milkweed bugs (Oncopeltus). Evolution 2, 371-385. doi: $10.1111 / j .1558-5646.1980 . t b 04825 . x$

Dingle, H., and Drake, V. A. (2007). What is migration? Bioscience 57, 113-121. doi: 10.1641/B570206

Dockx, C. (2007). Directional and stabilizing selection on wing size and shape in migrant and resident monarch butterflies, Danaus plexippus (L.), in Cuba. Biol. J. Linn. Soc. 92, 605-616. doi: 10.1111/j.1095-8312.2007.00886.x

Drake, V. A., and Gatehouse, A. G. (eds.). (1995). Insect Migration: Tracking Resources through Space and Time. Cambridge, UK: Cambridge University Press.

Dudley, R. (1995). "Aerodynamics, energetics and reproductive constraints of migratory flight in insects," in Insect Migration: Tracking Resources Through Space and Time, eds V. A. Drake and A. G. Gatehouse (Cambridge: Cambridge University Press), 303-319. doi: 10.1017/CBO9780511470875.015

Fairbairn, D. J. (1992). The origins of allometry: size and shape polymorphism in the common waterstrider, Gerris remigis Say (Heteroptera, Gerridae). Biol. J. Linn. Soc. 45, 167-186. doi: 10.1111/j.1095-8312.1992.tb00637.x 
Fairbairn, D. J., and Yadlowski, D. E. (1997). Coevolution of traits determining migratory tendency: correlated response of a critical enzyme, juvenile hormone esterase, to selection on wing morphology. J. Evol. Biol. 10, 495-513. doi: $10.1007 / \mathrm{s} 000360050038$

Flockhart, D. T. T., Dabydeen, A., Satterfield, D. A., Hobson, K. A., Wassenaar, L. I., and Norris, D. R. (2018). Patterns of parasitism in monarch butterflies during the breeding season in eastern North America. Ecol. Entomol. 43, 28-36. doi: $10.1111 /$ een. 12460

Flockhart, D. T. T., Wassenaar, L. I., Martin, T. G., Hobson, K. A., Wunder, M. B., and Norris, D. R. (2013). Tracking multi-generational colonization of the breeding grounds by monarch butterflies in eastern North America. Proc. $R$. Soc. B 280:20131087. doi: 10.1098/rspb.2013.1087

Fox, R., and Dennis, R. L. (2010). Winter survival of Vanessa atalanta (Linnaeus, 1758) (Lepidoptera: Nymphalidae): a new resident butterfly for Britain and Ireland? Entomol. Gaz. 61, 94-103.

Freeland, J. R., May, M., Lodge, R., and Conrad, K. F. (2003). Genetic diversity and widespread haplotypes in a migratory dragonfly, the common green darner Anax junius. Ecol. Entomol. 28, 413-421. doi: 10.1046/j.1365-2311.2003.00521.x

Gatehouse, A. G. (1994). Insect migration: variability and success in a capricious environment. Res. Popul. Ecol. 36, 165-171. doi: 10.1007/BF02514932

Gatehouse, A. G., and Zhang, X. -,X. (1995). "Migratory potential in insects: variation in an uncertain environment," in Insect Migration: Tracking Resources Through Space and Time, eds V. A. Drake and A. G. Gatehouse (Cambridge: Cambridge University Press), 193-242. doi: 10.1017/CBO9780511470875.011

Guerra, P. A., and Reppert, S. M. (2013). Coldness triggers northward flight in remigrant monarch butterflies. Curr. Biol. 23, 419-423. doi: 10.1016/j.cub.2013.01.052

Hallworth, M. T., Marra, P. P., McFarland, K. P., Zahendra, S., and Studds, C. E. (2018). Tracking dragons: stable isotopes reveal the annual cycle of a longdistance migratory insect. Biol. Lett. 14:20180741. doi: 10.1098/rsbl.2018.0741

Hansson, L.-A., and Hylander, S. (2009). Size-structured risk assessments govern Daphnia migration. Proc. R. Soc. B 276, 331-336. doi: 10.1098/rspb.2008.1088

Hegmann, J. P., and Dingle, H. (1982). "Phenotypic and genotypic covariance structure in milkweed bug life history traits," in Evolution and Genetics of Life Histories, eds H. Dingle and J. P. Hegmann (New York, NY: Springer-Verlag), 177-188. doi: 10.1007/978-1-4684-6270-8_11

Hobson, K. A., Soto, D. X., Paulson, D. R., Wassenaar, L. I., and Matthews, J. H. (2012). A dragonfly $\left(\delta^{2} \mathrm{H}\right)$ isoscape for North America: a new tool for determining natal origins of migratory aquatic emergent insects. Methods Ecol. Evol. 3, 766-772. doi: 10.1111/j.2041-210X.2012.00202.x

Holland, R. A., Wikelski, M., and Wilcove, D. S. (2006). How and why do insects migrate? Science 313, 794-796. doi: 10.1126/science.1127272

Hondelmann, P., and Poehling, H.-M. (2007). Diapause and overwintering of the hoverfly Episyrphus balteatus. Entomol. Exp. Appl. 124, 189-200. doi: 10.1111/j.1570-7458.2007.00568.x

Hu, G., Lim, K. S., Horvitz, N., Clark, S. J., Reynolds, D. R., Sapir, N., et al. (2016). Mass seasonal bioflows of high-flying insect migrants. Science 354, 1584-1587. doi: $10.1126 /$ science.aah4379

Hu, G., Lu, M.-H., Tuan, H. A., Liu, W.-C., Xie, M.-C., McInerney, C. E., et al. (2017). Population dynamics of rice planthoppers, Nilaparvata lugens and Sogatella furcifera (Hemiptera, Delphacidae) in Central Vietnam and its effects on their spring migration to China. Bull. Entomol. Res. 107, 369-381. doi: 10.1017/S0007485316001024

Hut, R. A., Paolucci, S., Dor, R., Kyriacou, C. P., and Daan, S. (2013). Latitudinal clines: an evolutionary view on biological rhythms. Proc. R. Soc. B 280, 1-9. doi: $10.1098 /$ rspb.2013.0433

Jahn, A. E., Levey, D. J., Hostetler, J. A., and Mamani, A. M. (2010). Determinants of partial bird migration in the Amazon Basin. J. Anim. Ecol. 79, 983-992. doi: $10.1111 / j .1365-2656.2010 .01713 . x$

Johnson, C. G. (1969). Migration and Dispersal of Insects by Flight. London: Methuen.

Kent, J. W., and Rankin, M. A. (2001). Heritability and physiological correlates of migratory tendency in the grasshopper Melanoplus sanguinipes. Physiol. Entomol. 26, 371-380. doi: 10.1046/j.0307-6962.2001.00257.x

Ketterson, E. D., and Nolan, V. Jr. (1976). Geographic variation and its climatic correlates in the sex ratio of eastern-wintering dark-eyed juncos (Junco hyemalis hyemalis). Ecology 57, 679-693. doi: 10.2307/19 36182

Kissling, W. D., Pattemore, D. E., and Hagen, M. (2014). Challenges and prospects in the telemetry of insects. Biol. Rev. 89, 511-530. doi: 10.1111/brv. 12065

Knight, S. M., Pitman, G. M., Flockhart, D. T. T., and Norris, D. R. (2019). Radiotracking reveals how wind and temperature influence the pace of daytime insect migration. Biol. Lett. 15:20190327. doi: 10.1098/rsbl.2019.0327

Kokko, H. (2011). Directions in modelling partial migration: how adaptation can cause a population decline and why the rules of territory acquisition matter. Oikos 120, 1826-1837. doi: 10.1111/j.1600-0706.2011.19438.x

Krauel, J. J., Westbrook, J. K., and McCracken, G. F. (2015). Weather-driven dynamics in a dual-migrant system: moths and bats. J. Anim. Ecol. 84, 604-614. doi: $10.1111 / 1365-2656.12327$

Lack, D. (1943). The problem of partial migration. Br. Birds 37, 122-130.

Lin, X., Xu, Y., Jiang, J., Lavine, M., and Lavine, L. C. (2018). Host quality induces phenotypic plasticity in a wing polyphenic insect. Proc. Natl. Acad. Sci. U.S.A. 115, 7563-7568. doi: 10.1073/pnas.1721473115

Luder, K., Knop, E., and Menz, M. H. M. (2018). Contrasting responses in community structure and phenology of migratory and non-migratory pollinators to urbanization. Div. Dist. 24, 919-927. doi: 10.1111/ddi.12735

Lundberg, P. (1988). The evolution of partial migration in birds. Trends Ecol. Evol. 3, 172-175. doi: 10.1016/0169-5347(88)90035-3

Matsumura, M. (1996). Genetic analysis of a threshold trait: density-dependent wing dimorphism in Sogatella furcifera (Horváth) (Hemiptera: Delphacidae), the whitebacked planthopper. Heredity 76, 229-237. doi: 10.1038/hdy.1996.36

May, M. L., Gregoire, J. A., Gregoire, S. M., Lubertazzi, M. A., and Matthews, J. H. (2017). Emergence phenology, uncertainty, and the evolution of migratory behavior in Anax junius (Odonata: Aeshnidae). PLoS ONE 12:e0183508. doi: 10.1371/journal.pone.0183508

Minter, M., Pearson, A., Lim, K. S., Wilson, K., Chapman, J. W., and Jones, C. M. (2018). The tethered flight technique as a tool for studying life-history strategies associated with migration in insects. Ecol. Entomol. 43, 397-411. doi: 10.1111/een.12521

Müller, C. B., Williams, I. S., and Hardie, J. (2001). The role of nutrition, crowding and interspecific interactions in the development of winged aphids. Ecol. Entomol. 26, 330-340. doi: 10.1046/j.1365-2311.2001.00321.x

Mun, J. H., Song, Y. H., Heong, K. L., and Roderick, G. K. (1999). Genetic variation among Asian populations of rice planthoppers, Nilaparvata lugens and Sogatella furcifera (Hemiptera: Delphacidae): mitochondrial DNA sequences. Bull. Entomol. Res. 89, 245-253. doi: 10.1017/S000748539900036X

Mysterud, A., Loe, L. E., Zimmerman, B., Bischof, R., Veiberg, V., and Meisingset, E. (2011). Partial migration in expanding red deer populations at northern latitudes - a role for density dependence. Oikos 120, 1817-1825. doi: 10.1111/j.1600-0706.2011.19439.x

Naranjo, S. E. (2019). Assessing insect flight behavior in the laboratory: a primer on flight mill methodology and what can be learned. Ann. Entomol. Soc. Am. 112, 182-199. doi: 10.1093/aesa/say041

Niitepõld, K., Smith, A. D., Osborne, J. L., Reynolds, D. R., Carreck, N. L., Martin, A. P., et al. (2009). Flight metabolic rate and Pgi genotype influence butterfly dispersal rate in the field. Ecology 90, 2223-2232. doi: 10.1890/081498.1

Nijhout, H. F. (1999). Control mechanisms of polyphenic development in insects. Bioscience 49, 181-192. doi: 10.2307/1313508

Nilsson, A. L. K., Nilsson, J.-Å., and Alerstam, T. (2011). Basal metabolic rate and energetic cost of thermoregulation among migratory and resident blue tits. Oikos 120, 1784-1789. doi: 10.1111/j.1600-0706.2011.19440.x

Odermatt, J., Frommen, J. G., and Menz, M. H. M. (2017). Consistent behavioural differences between migratory and resident hoverflies. Anim. Behav. 127, 187-195. doi: 10.1016/j.anbehav.2017.03.015

Ogawa, K., and Miura, T. (2014). Aphid polyphenisms: trans-generational developmental regulation through viviparity. Front. Physiol. 5:1. doi: 10.3389/fphys.2014.00001

Oostra, V., De Jong, M. A., Invergo, B. M., Kesbeke, F., Wende, F., Brakefield, P. M., et al. (2011). Translating environmental gradients into discontinuous reaction norms via hormone signalling in a polyphenic butterfly. Proc. R. Soc. B 278, 789-797. doi: 10.1098/rspb.2010.1560 
Pulido, F. (2011). Evolutionary genetics of partial migration - the threshold model of migration revis(it)ed. Oikos 120, 1776-1783. doi: 10.1111/j.1600-0706.2011.19844.x

Rankin, M. A., and Burchsted, J. C. A. (1992). The cost of migration in insects. Ann. Rev. Entomol. 37, 533-539. doi: 10.1146/annurev.en.37.010192.002533

Rankin, M. A., McAnelly, M. L. and Bodenhamer, J. E. (1986). "The oogenesisflight syndrome revisited," in Insect Flight: Dispersal and Migration, ed W. Danthanarayana (Berlin; Heidelberg: Springer-Verlag), 27-38. doi: 10.1007/978-3-642-71155-8 3

Raymond, L., Plantegenest, M., Gauffre, B., Sarthou, J.-P., and Vialatte, A. (2013). Lack of genetic differentiation between contrasted overwintering strategies of a major pest predator Episyrphus balteatus (Diptera: Syrphidae): implications for biocontrol. PLoS ONE 8:e72997. doi: 10.1371/journal.pone.0072997

Raymond, L., Sarthou, J. P., Plantegenest, M., Gauffre, B., Ladet, S., and Vialatte, A. (2014a). Immature hoverflies overwinter in cultivated fields and may significantly control aphid populations in autumn. Agric. Ecosyst. Environ. 185, 99-105. doi: 10.1016/j.agee.2013.12.019

Raymond, L., Vialatte, A., and Plantegenest, M. (2014b). Combination of morphometric and isotopic tools for studying spring migration dynamics in Episyrphus balteatus. Ecosphere 5, 1-16. doi: 10.1890/ES14-00075.1

Roff, D. A. (1994). The evolution of dimorphic traits: predicting the genetic correlation between environments. Genetics 136, 395-401.

Roff, D. A. (1996). The evolution of threshold traits in animals. Q. Rev. Biol. 71, 3-35. doi: 10.1086/419266

Roff, D. A. (2011). Alternative strategies: the evolution of switch points. Curr. Biol. 21, R285-R287. doi: 10.1016/j.cub.2011.03.016

Roff, D. A., and Fairbairn, D. J. (1991). Wing dimorphism and the evolution of migratory polymorphisms among the Insecta. Am. Zool. 31, 243-251. doi: $10.1093 / \mathrm{icb} / 31.1 .243$

Roff, D. A., and Fairbairn, D. J. (2007). The evolution and genetics of migration in insects. Bioscience 57, 155-164. doi: 10.1641/B570210

Roff, D. A., Stirling, G., and Fairbairn, D. J. (1997). The evolution of threshold traits: a quantitative genetic analysis of the physiological and life-history correlates of wing dimorphism in the sand cricket. Evolution 51, 1910-1919. doi: 10.1111/j.1558-5646.1997.tb05113.x

Ruiz Vargas, N., Rowe, L., Stevens, J., Armagost, J. E., Johnson, A. C., and Malcolm, S. B. (2018). Sequential partial migration across monarch generations in Michigan. Anim. Migr. 5, 104-114. doi: 10.1515/ami2018-0007

Sappington, T. W., and Showers, W. B. (1992). Reproductive maturity, mating status, and long-duration flight behaviour of Agrotis ipsilon (Lepidoptera: Noctuidae) and the conceptual misuse of the oogenesis-flight syndrome by entomologists. Env. Entomol. 21, 677-688. doi: 10.1093/ee/21.4.677

Satterfield, D. A., Maerz, J. C., and Altizer, S. (2015). Loss of migratory behaviour increases infection risk for a butterfly host. Proc. R. Soc. B. 282:20141734. doi: 10.1098/rspb.2014.1734

Satterfield, D. A., Maerz, J. C., Hunter, M. D., Flockhart, D. T. T., Hobson, K. A., Norris, D. R., et al. (2018). Migratory monarchs that encounter resident monarchs show life-history differences and higher rates of parasite infection. Ecol. Lett. 21, 1670-1680. doi: 10.1111/ele.13144

Satterfield, D. A., Villablanca, F. X., Maerz, J. C., and Altizer, S. (2016). Migratory monarchs wintering in California experience low infection risk compared to monarchs breeding year-round on non-native milkweed. Integr. Comp. Biol. 56, 343-352. doi: 10.1093/icb/icw030

Shaw, A. K., and Levin, S. A. (2011). To breed or not to breed: a model of partial migration. Oikos 120, 1871-1879. doi: 10.1111/j.1600-0706.2011.19443.x

Slager, B. H., and Malcolm, S. B. (2015). Evidence for partial migration in the southern monarch butterfly, Danaus erippus, in Bolivia and Argentina. Biotropica 47, 355-362. doi: 10.1111/btp.12206

Southwood, T. R. E. (1962). Migration of terrestrial arthropods in relation to habitat. Biol. Rev. 37, 171-214. doi: 10.1111/j.1469-185X.1962.tb0 1609.x
Sparks, T. H., Roy, D. B., and Dennis, R. L. H. (2005). The influence of temperature on migration of Lepidoptera into Britain. Glob. Change Biol. 11, 507-514. doi: 10.1111/j.1365-2486.2005.00910.x

Stefanescu, C., Páramo, F., Åkesson, S., Alarcón, M., Ávila, and A., Brereton, T., et al. (2013). Multi-generational long-distance migration of insects: studying the painted lady butterfly in the Western Palaearctic. Ecography 36, 474-486. doi: 10.1111/j.1600-0587.2012.07738.x

Suchan, T., Talavera, G., Sáez, L., Ronikier, M., and Vila, R. (2019). Pollen metabarcoding as a tool for tracking long-distance insect migrations. Mol. Ecol. Res. 19, 149-162. doi: 10.1111/1755-0998.12948

Taylor, L. R. and Taylor, R. A. J. (1983). "Insect migration as a paradigm for survival by movement" in The Ecology of Animal Movement, eds L. R. Swingland and P. J. Greenwood (Oxford: Oxford University Press), 181-214.

Tigreros, N., and Davidowitz, G. (2019). Flight-fecundity tradeoffs in wing-monomorphic insects. Adv. Insect Phys. 56, 1-41. doi: 10.1016/bs.aiip.2019.02.001

Tomlinson, S., and Menz, M. H. M. (2015). Does metabolic rate and evaporative water loss reflect differences in migratory strategy in sexually dimorphic hoverflies? Comp. Biochem. Physiol. A 190, 61-67. doi: 10.1016/j.cbpa.2015.09.004

Trottier, R. (1971). Effect of temperature on the life-cycle of Anax junius (Odonata, Aeshnidae) in Canada. Can. Entomol., 103, 1671-1683. doi: 10.4039/Ent1031671-12

Vander Zanden, H. B., Chaffee, C. L., Gonzalez-Rodriguez, A., Flockhart, D. T. T., Norris, D. R., and Wayne, M. L. (2018). Alternate migration strategies of eastern monarch butterflies revealed by stable isotopes. Anim. Migr. 5, 74-83. doi: 10.1515/ami-2018-0006

Vellichirammal, N. N., Gupta, P., Hall, T. A., and Brisson, J. A. (2017). Ecdysone signaling underlies the pea aphid transgenerational wing polyphenism. Proc. Natl. Acad. Sci. U.S.A. 114, 1419-1423. doi: 10.1073/pnas.1617640114

Warrant, E., Frost, B., Green, K., Mouritsen, H., Dreyer, D., Adden, A., et al. (2016). The Australian bogong moth Agrotis infusa: a long-distance nocturnal navigator. Front. Behav. Neurosci. 10:77. doi: 10.3389/fnbeh.2016.00077

Wikelski, M., Moskowitz, D., Adelman, J. S., Cochran, J., Wilcove, D. S., and May, M. L. (2006). Simple rules guide dragonfly migration. Biol. Lett. 2, 325-329. doi: 10.1098/rsbl.2006.0487

Wilson, K. (1995). "Insect migration in heterogeneous environments," in Insect Migration: Tracking Resources Through Space and Time, eds V. A. Drake and A. G. Gatehouse (Cambridge: Cambridge University Press), 243-264. doi: 10.1017/CBO9780511470875.012

Wotton, K. R., Gao, B., Menz, M. H. M., Morris, R. K. A., Ball, S. G., Reynolds, D. R., et al. (2019). Mass seasonal migrations of hoverflies provide extensive pollination and crop protection services. Curr. Biol. 29, 2167-2173. doi: 10.1016/j.cub.2019.05.036

Zera, A. J., and Denno, R. F. (1997). Physiology and ecology of dispersal polymorphism in insects. Annu. Rev. Ent. 42, 207-230. doi: 10.1146/annurev.ento.42.1.207

Zhan, S., Zhang, W., Niitepõld, K., Hsu, J., Haeger, J. F., Zalucki, M. P., et al. (2014). The genetics of monarch butterfly migration and warning colouration. Nature 514, 317-321. doi: 10.1038/nature13812

Conflict of Interest: The authors declare that the research was conducted in the absence of any commercial or financial relationships that could be construed as a potential conflict of interest.

Copyright (๑ 2019 Menz, Reynolds, Gao, Hu, Chapman and Wotton. This is an open-access article distributed under the terms of the Creative Commons Attribution License (CC BY). The use, distribution or reproduction in other forums is permitted, provided the original author(s) and the copyright owner(s) are credited and that the original publication in this journal is cited, in accordance with accepted academic practice. No use, distribution or reproduction is permitted which does not comply with these terms. 